\title{
O trabalho docente no curso.Técnico de Enfermagem em uma Etec
}

\author{
Mariana Lauriano1, Kátia Teresinha Alves Rezende, ${ }^{2}$ \\ Silvia Franco da Rocha Tonhom ${ }^{2}$, lone Ferreira Santos ${ }^{2}$, \\ Aline Pereria de Souza ${ }^{3}$ \\ ${ }^{1}$ Estudante do Curso Técnico de Enfermagem da Etec Antônio Devisate de Marilia, Brasil | \\ mariana.p.lauriano1904@gmail.com | https://orcid.org/0000-0002-9312-1172 \\ ${ }^{2}$ Docente do Curso de Enfermagem da Faculdade de Medicina de Marilia (Famema), Brasil | \\ katialvesrezende@gmail.com; siltonhom@gmail.com; ionefs13@gmail.com | \\ https://orcid.org/0000-0002-9022-2680; https://orcid.org/0000-0001-7522-2861; \\ https://orcid.org/0000-0002-2030-4541 \\ ${ }^{3}$ Enfermeira, mestranda pelo Programa de Mestrado Acadêmico "Saúde e Envelhecimento" \\ da Faculdade de Medicina de Marilia (Famema), Brasil | aline.psouza_enfer@hotmail.com | \\ https://orcid.org/0000-0003-4395-1482

\begin{abstract}
Resumo: Este estudo teve como objetivo analisar o desenvolvimento do trabalho dos docentes que atuam no curso técnico de enfermagem em uma escola técnica de um município de médio porte. Os docentes de enfermagem foram os participantes. Utilizamos um roteiro semiestruturado para a coleta de dados enviados por e-mail. A análise de dados foi realizada por meio da análise de conteúdo na modalidade temática. Apresenta-se três temáticas, a saber: Potências do trabalho docente; enunciando os desafios de ser docente e por fim, refletindo acerca de estratégias para a superação dos desafios de ser docente. Depreende-se que os desafios enfrentados pelos docentes do curso Técnico de Enfermagem interferem no seu adoecimento, sugerindo a importância de estudos que refletem de forma mais ampliada essa realidade e o olhar mais cauteloso das autoridades competentes para minimizar esse problema.
\end{abstract}

Palavras-chave: Docente de Enfermagem; Educação Profissionalizante; Prática do Docente de Enfermagem.

\section{The Teaching Work in the Course Nursing Technician in an Etec}

Abstract: The objective of this study was to outline a profile of teachers who work in the technical nursing course at a technical school in a municipality. Nursing professors were the participants. We used a semi-structured script to collect data sent by email. Data analysis was carried out through content analysis in the thematic modality. At this moment, three themes are presented, namely: The teaching work; Enunciating the challenges of being a teacher and finally, Reflecting on strategies for overcoming the challenges of being a teacher. It appears that the challenges faced by the professors of the Nursing Technician course interfer with their illness, suggesting the importance of studies that reflect this reality more broadly and the more cautious look of the competent authorities to minimize this problem.

Keywords: Nursing Professor; Vocational Education; Nursing Teacher Practice.

\section{Introdução}

O atual modelo de atenção à saúde estabelece a integralidade como um princípio ou diretriz que contempla as dimensões biológicas, psicológicas e sociais do processo saúde-doença mediante a promoção, proteção, recuperação e reabilitação, além de incluir a humanização do cuidado, difundido como uma nova cultura da saúde na educação profissional (Centro estadual de educação tecnológica Paula Souza, 2018).

Para atender às necessidades da área de Saúde é necessário preparar o profissional ao pleno exercício de suas funções mentais, cognitivas e socioafetivas, com capacidade de aprender com autonomia e assimilar o crescente número de informações, adquirir novos conhecimentos e habilidades e enfrentar situações inéditas com dinamismo, flexibilidade e criatividade, compreendendo as bases sociais, econômicas, técnicas e científicas (Centro estadual de educação tecnológica Paula Souza, 2018). 
Assim, está revisão de paradigmas e pressupostos dessa área profissional pressupõe uma redefinição dos perfis dos trabalhadores de Saúde, o que justifica a reformulação do plano de curso da habilitação de Técnico em Enfermagem, proposto pelo Centro Paula Souza para acompanhar as transformações tecnológicas e socioculturais do mundo do trabalho, especialmente na área da Saúde e no campo da Enfermagem (Centro estadual de educação tecnológica Paula Souza, 2018).

A partir dessas premissas a Escola Técnica vinculada ao Centro Estadual de Educação Tecnológica Paula Souza, autarquia da Secretaria do Desenvolvimento Econômico, Ciência, Tecnologia e Inovação do Governo do Estado de São Paulo, a Etec Antônio Devisate oferece uma diversidade de cursos técnicos, dentre eles, o Técnico de Enfermagem.

Identifica-se que a problemática atual do curso é o número alto e frequente de licenças dos docentes para tratamento de saúde. Pressupõe que os desafios enfrentados pelos docentes no desenvolvimento do trabalho estejam interferindo nesse contexto. Então, questiona-se: como está ocorrendo o desenvolvimento do trabalho dos docentes no Curso técnico?

Assim, essa pesquisa objetivou analisar o desenvolvimento do trabalho dos docentes que atuam no curso técnico de enfermagem da ETEC.

\section{Metodologia}

Trata se de uma pesquisa qualitativa, a qual se aplica ao estudo da história, das relações, das representações, das crenças, das percepções e das opiniões, produtos das interpretações que os humanos fazem a respeito de como vivem, sentem e pensam. Propicia a construção de novas abordagens, revisão e criação de novos conceitos e categorias durante a investigação (Minayo, 2014).

Realizou-se o estudo na Etec Antonio Devisate no interior paulista, sendo está uma Escola Técnica vinculada ao Centro Estadual de Educação Tecnológica Paula Souza, autarquia da Secretaria do Desenvolvimento Econômico, Ciência, Tecnologia e Inovação do Governo do Estado de São Paulo. Foram convidados a participar da pesquisa mediante o Termo de Consentimento Livre Esclarecido (TCLE) o corpo docente do curso técnico de enfermagem da Etec, o qual compreende 15 profissionais.

A coleta de dados foi por meio de questionários enviados via e-mail. $O$ instrumento de coleta é composto pelos dados de identificação e a questão norteadora. A identificação compreende: nome, idade, gênero, estado civil, categoria e formação profissional e a questão norteadora consiste em descrever o trabalho como docente no curso técnico de enfermagem. Dez professores responderam e enviaram o questionário via e-mail. A coleta ocorreu no mês de agosto de 2020 e os dados transcritos por duas pesquisadoras.

Submeteu-se os dados à Análise de Conteúdo na Modalidade Temática, sendo um conjunto de estratégias para extrair dos discursos diversificados seus sentidos e significados. Dá-se da busca dos "núcleos de sentidos" inseridos em uma comunicação, confrontando-os com o objetivo do estudo e referencial teórico (Minayo, 2016).

Os dados passaram por ordenamento e organização do material empírico, seguidos da compreensão deste. Deu-se a transição entre o empírico e a elaboração teórica, com apropriação das informações obtidas. Logo, a elaboração das unidades de sentido, a correlação com a teorização existente e, por fim, o texto final (Minayo, 2014). As temáticas foram feitas inicialmente por 3 pesquisadoras e, após, as demais autoras validaram. Criou-se 3 temas eixos norteadores à discussão dos resultados. A interpretação dos resultados foi pautada na integralidade do cuidado em saúde, compreendida como eixo prioritário da atual Política Nacional de Saúde (Pinheiro et al, 2001) 
Esta pesquisa foi aprovada em 21 de fevereiro de 2020, pelo Comitê de Ética em Pesquisa (CEP) envolvendo Seres Humanos da Faculdade de Medicina de Marília-SP sob Parecer Consubstanciado de 꾸․852.852 e Certificado de Apresentação para Apreciação Ética (CAAE): 28894920.1.0000.5413.

\section{Resultados}

Os 10 docentes entrevistados eram enfermeiros; a maioria casado (80\%); eles estavam na faixa etária entre 30 a 60 anos, sendo que metade deles (50\%) tinha entre 41 a 50 anos. Em relação capacitaçao para docência, a maioria (80\%) referiu ter realizado cursos de capacitação, sem mais especificações sobre eles e poucos $(20 \%)$ referiram pós-graduação em nível Mestrado.

Foram identificadas três temáticas: potências do trabalho docente; enunciando os desafios de ser docente e refletindo acerca de estratégias para superação dos desafios de ser docente.

\subsection{Potências do Trabalho Docente}

Em relação a abordagem acerca do trabalho docente, emergiram-se depoimentos que enfatizam a gratificação desse trabalho, ressalta-se as possibilidades de aproximação com a prática profissional, a atuação com estudantes e o prazer à construção conjunta dos conhecimentos.

"Eu gosto bastante de atuar como docente do curso técnico de enfermagem, pois me aproxima da prática, da assistência de enfermagem, coisa que, devido as minhas escolhas profissionais, acabei me afastando nos últimos anos" (P2).

"O trabalho como docente é uma atividade bastante prazerosa, estar com os estudantes é uma experiência ímpar" (P8).

Destaca-se a utilização de estratégias de metodologias ativas e ferramentas ao desenvolvimento de atividades remotas.

"Na parte teórico-prática procuro utilizar metodologias ativas como simulação realística, aula invertida, estudo de caso e games(...)Trabalho também com a plataforma Moodle e com projetos no componente de Desenvolvimento de Trabalho de Conclusão de Curso" (P6).

Enfatiza-se a necessidade da formação de profissionais com ética, responsabilidade e compromisso.

"Contribuir na construção do conhecimento dos discentes para que sejam competentes a exercer a enfermagem com ética, responsabilidade, compromisso" (P10).

\subsection{Enunciando os Desafios de Ser Docente}

Evidencia-se aspectos relacionados às condições de trabalho, tais como: à sobrecarga de trabalho; baixa remuneração; cansaço; alto índices de absenteísmos; uso de novas tecnologias; dificuldades no manejo com determinados comportamentos do estudante, e limitações do mesmo no processo ensino aprendizagem.

Referem sobre a necessidade de ter mais de um emprego, levando a sobrecarga de trabalho, porém, não reconhece o adoecimento para não ter prejuízos na carreira profissional. 
"Um discurso muito comum entre os docentes é o cansaço, pois, como a docência no curso técnico não remunera o suficiente, muitos acumulam com outros empregos ou lecionam em muitos períodos" (P2).

"temos um problema relacionado a isso, em alguns momentos nos deparamos com professores as vezes sem condições de trabalhar com atestado que não foi apresentado na instituição pois no final acaba sendo prejudicado na pontuação docente e no bônus. Devido a isso o número é baixo e "não podemos ficar doente" (P5).

Aponta-se como desafio a necessidade de constante capacitação para oportunizar a construção de novos conhecimentos e transformação dos processos dos estudantes.

"Não é uma tarefa tão fácil, precisamos nos dedicar muito a pesquisa para sermos mediadores da aprendizagem e sermos capazes de produzir novos conhecimentos e incentivar os alunos a busca de novos saberes" (P4).

Denota-se limites nas possibilidades de aprendizagem de estudantes que trabalham e estudam.

"Alunos que trabalham e estudam apresentam dificuldades de estudar e realizar as atividades solicitadas e as vezes de acompanhar o ensino" (P5).

Soma-se a isso, a percepção de estudantes que, por vezes, ingressam no curso com pouca clareza a respeito da profissão, fragilizando o processo em curso.

"Alunos desestimulados e desinteressados que as vezes ingressam no curso muito jovens sem saber ao certo se é a profissão que querem seguir e acabam não participando como deveria e até mesmo atrapalhando os interessados" (P5).

\subsection{Refletindo acerca de Estratégias para Superação dos Desafios de Ser Docente}

Com relação as estratégias frente aos desafios que o exercício da docência pressupõe, identifica-se a importância de constante atualização, motivação, aberto aos processos e estimular os estudantes aos novos conhecimentos.

"Motivação em aprender constantemente e renovar os conhecimentos, com atualizações contínuas, motivando ao estudante a buscar o conhecimento, desenvolve-lo também como pessoa, cidadão, com consciência crítica e reflexiva na profissão e na equipe de saúde" (P1).

"Nunca deixar de aprender, o ser educador é uma missão e para tal faz-se necessário estar em constante movimento de dar e receber, de aprender a aprender" (P3).

"Ser professor não é só estudar, fazer cursos de capacitação e pósgraduação para ter conhecimento e estar atualizado. É estar aberto, disposto a mudar, a tentar algo diferente, uma nova abordagem, um novo método" (P2).

Relatam a aproximação com o estudante para compreensão de suas necessidades e busca de superação.

"Acho que o professor tem que estar mais próximo do aluno para trazer interesse no aprendizado e ser capaz de estimular e mediar a construção do conhecimento, desenvolvendo laços de afinidade, respeito, confiança e afeto com os seus alunos, tão importantes para o bom desenvolvimento do processo ensino-aprendizagem e o uso de metodologias diversificadas e atividades diferenciadas para que todos tenham a oportunidade de aprender" (P5). 
"As estratégias utilizadas vão ao encontro de identificar as fragilidades e potencialidades de cada aluno e buscar saná-las da melhor forma possível; utilizar de recursos inovadores no ensino-aprendizagem; capacitação docente frente as metodologias ativas; incentivo à pesquisa científica e inserção dos alunos em cenários práticos" (P6).

"Vejo que as estratégias são ser criativo, e ter conhecimento teórico prático" (P4).

Considerando o cenário atual decorrente da situação pandêmica, destaca-se a necessidade da utilização de novas tecnologias como ferramentas inerentes ao processo ensino aprendizagem e identifica-se limites de acesso dos estudantes.

"Destacam-se no atual cenário as limitações do ensino remoto à distância, demandando que o docente se adeque da melhor forma possível as novas formas de executar seu trabalho, exigindo do mesmo o uso de novas tecnologias de ensino e também a sensibilidade de identificar as necessidades de cada aluno" (P7).

Ressalta-se a importância do fortalecimento do docente para não ocorrer o adoecimento.

"A principal estratégia é não adoecer pelos desafios que são diários, uma boa higiene mental se faz necessário, já que os desafios são diários” (P8).

\section{Discussão}

Atualmente observa-se aumento de enfermeiros bacharéis na função docente. A Portaria Ministerial n.13/69 - MEC, instituiu a Licenciatura em Enfermagem para a formação pedagógica do enfermeiro e o direito ao registro definitivo como professor das disciplinas e atividades relacionadas à enfermagem, higiene e aos programas de saúde em nível médio. O perfil educacional do enfermeiro consolida-se mediante o módulo pedagógico em seu currículo de graduação ou por Curso de Licenciatura Plena em Enfermagem na Faculdade de Educação pelo processo de seleção às vagas de aproveitamento de estudos.

Evidencia-se a fragilidade na formação dos professores estudados para exercerem a docência e alguns outros estudos apresentaram resultados semelhantes.

Silva et al, 2015 referem que 67\% dos professores têm formação em Bacharelado, 33\% com formação em Licenciatura, $25 \%$ do corpo docente possui experiência relativamente baixa na prática de enfermagem e $8 \%$ nunca atuaram como enfermeiros assistenciais. Sugerem mais investigações e seriedade nesse trabalho, estudos e reflexões acerca da docência em Cursos Técnicos de Enfermagem, pois trata-se de formação de profissionais ao cuidado de pessoas debilitadas e na pior fase de suas vidas.

Sgarbi et al, 2018 evidenciou incipiente o preparo sistematizado ao desempenho desta função por falta de formação pedagógica para atuar na docência. Revela que foi a partir da reflexão sobre suas práticas diárias em instituições de saúde que se estabeleceram docentes.

Atualmente, ainda que tenha se dado expressiva ampliação das escolas de nível técnico em enfermagem, não houve uma preocupação sistemática, com a formação pedagógica dos enfermeiros que atuam na formação de novos profissionais (Ferreira Júnior, 2008), ainda que haja grandes debates acerca da prática pedagógica do enfermeiro docente em consonância às Diretrizes Curriculares para o Curso de Graduação em Enfermagem (Rodrigues \& Sobrinho, 2007).

Mesmo assim, os professores denotam otimismo para esse trabalho, pois encontram prazer de atuação quando buscam a aproximação e articulação entre teoria e prática, com os estudantes e a construção conjunta do conhecimento, ressaltando sua responsabilidade e necessidade de capacitação ao trabalho. 
Essas falas nos remete as grandes reflexões sobre currículos integrados, aprendizagem significativa e os métodos ativos de aprendizagem.

No currículo integrado pretende-se que o estudante seja capaz de refletir sobre sua condição social, participar de lutas em favor dos interesses da coletividade e a proposta de formação vinculado aos interesses de mercado. Os estudantes desenvolvem a experimentação e as práticas de estudo e investigação; isso requer do docente uma atitude diferenciada, sendo necessário um processo de formação inicial e continuada que o capacite. Refere-se que as Diretrizes Curriculares Nacionais do Ensino Médio DCNEM (BRASIL, DCNEM, 1998) têm o trabalho como princípio educativo e que o ser humano é produtor da sua realidade da qual se apropria e pode transformá-la (Azevedo et al, 2015).

Moreira, 2006 em uma descrição detalhada sobre a aprendizagem significativa na visão clássica de David Ausubel, refere que:

"...aprendizagem significativa se caracteriza pela interação entre conhecimentos prévios e conhecimentos novos, e que essa interação é nãoliteral e não-arbitrária. Nesse processo, os novos conhecimentos adquirem significado para o sujeito e os conhecimentos prévios adquirem novos significados ou maior estabilidade cognitiva" (Moreira; 2006; p.2).

Segundo Lima et al, 2019 as metodologias ativas de ensino aprendizagem visam promover a pró atividade, por meio do comprometimento dos educandos no processo educacional; a vinculação da aprendizagem aos aspectos significativos da realidade; o desenvolvimento do raciocínio e de capacidades à intervenção na própria realidade, à colaboração e cooperação entre participantes.

Tais compreensões denota mudança nos paradigmas da formação de profissionais da saúde, divergindo dos princípios do método tradicional.

Identifica-se potencialidades do uso da PBL na saúde. Infere-se que este processo pode oportunizar a capacidade de integrar a realidade do estudante à educação profissional e delinear contribuições à educação em saúde, a fim de fortalecer a construção do conhecimento científico de forma integral e humanizada (Silva et al, 2019).

Revela-se, com a pandemia da Covid-19, novos desafios como migrar do ensino presencial para ambientes virtuais. Assim, destaca-se a conexão, a apropriação das plataformas digitais e a falta de interesse dos alunos (Rocha \& Borges 2021). Porém, os professores buscaram transpor as dificuldades para tornar o ensino remoto interativo, dinâmico e motivador.

Soma-se, as vivências de prazer e sofrimento no trabalho dos docentes. Aponta-se como fatores desencadeantes a sobrecarga de trabalho, falta de reconhecimento, desvalorização social e má remuneração (Lima et al; 2019). Aspectos estes que corroboram com os encontrados na presente pesquisa. Os mesmos autores sugerem que o trabalho em cooperação e com reconhecimento são condições favoráveis à transformação do sofrimento.

\section{Conclusão}

A pesquisa possibilitou compreender o desenvolvimento do trabalho docente em um curso técnico em enfermagem. Pôde-se observar que os professores sentem prazer no desenvolvimento do seu trabalho e se desafiaram, introduzindo estratégias inovadoras de ensino-aprendizagem, buscando a motivação dos estudantes.

São grandes os desafios apresentados para o desenvolvimento do seu trabalho de educador. Destaca-se os aspectos sociais e institucionais como a sobrecarga de trabalho, baixa remuneração, cansaço, altos índices de absenteísmos, uso de novas tecnologias; e aos contextos de vida dos estudantes que dificultam no seu processo de formação. 
As sugestões para superar os desafios estão focadas na capacitação dos professores para desenvolverem um trabalho mais qualificados na formação desses estudantes, aproximando mais a relação entre eles com vistas à prevenção do adoecimento dos professores.

Assim, confirma-se o pressuposto de que os desafios enfrentados pelos docentes do curso Técnico de Enfermagem interferem no seu adoecimento, sugerindo a importância de estudos que refletem de forma mais ampliada essa realidade e o olhar mais cauteloso das autoridades competentes para minimizar esse problema.

Diante da pandemia da covi-19 foi necessária a mudança na estratégia da coleta de dados, no entanto, o conteúdo captado nos questionários possibilitou a realização da análise qualitativa, e oportunizou compreender as potências e os desafios de ser docente no Curso Técnico em Enfermagem.

\section{Referências}

Centro estadual de educação tecnológica Paula Souza. Plano de curso atualizado de acordo com a matriz curricular homologada para o $1^{\circ}$ semestre de 2018. São Paulo:CPS, 2018. Disponível em: http://devisate.com.br/n//wp-content/uploads/2018/06/Enfermagem.pdf. Acesso em: 5 jun. 2019.

Minayo, M. C. S. (2014). O desafio do conhecimento: pesquisa qualitativa em saúde (13 ed.). São Paulo (SP): Hucitec.

Minayo, M. C. S., Diniz, Debora, \& Gomes, R (2016). O artigo qualitativo em foco. Ciência \& Saúde Coletiva, 21(8), 2326. https://doi.org/10.1590/1413-81232015218.15592016

Pinheiro R, Mattos R.A., organizadores. Construção Social da Demanda: direito à saúde, trabalho em equipe e participação em espaços públicos. Rio de Janeiro: CEPESC/UERJ:Abrasco 2001.

Parecer COREN/SP n. 52, de 2003. Dispõe sobre docência para o enfermeiro lecionar. Disponível em:https://portal.corensp.gov.br/sites/default/files/Orienta\%C3\%A7\%C3\%A30\%20Fundamen tada\%20-\%20052

Silva, M. F., Braun, J. R., Lima, I. T. C., (2015). Caracterização do perfil dos professores que atuam no curso técnico de enfermagem no colégio estadual Jorge Schimmelpfeng da cidade de Foz do Iguaçu. Revista Eletrônica Cientifica Inovação e Tecnologia, v.1, n. 11, p. 2175-1846.

Sgarbi, A. K. G., Missio, L., Renovato, R. D., \& Hortelan, M. P. da S. M. (2018). Enfermeiro docente no ensino técnico em enfermagem. Laplage Em Revista, 4(1), p.254-273.

Ferreira junior, M. A. Os reflexos da formação inicial na atuação dos professores enfermeiros. Revista Brasileira de Enfermagem, Brasília, DF, v. 61, n. 6, dez. 2008.

Rodrigues, M. T. P.; Sobrinho, J. A. De c. M. Enfermeiro professor: um diálogo com a formação pedagógica. Revista Latino - Americana de Enfermagem, Brasília, v. 60, n. 4, p. 1-13, jul./ago. 2007.

Azevedo, M. A., Silva, C. D., Medeiros, D. L. M. (2015). Educação profissional e currículo integrado para o ensino médio: elementos necessários ao protagonismo juvenil. Ciência e Tecnologia. DOI: 10.15628/holos.2015.3190.

Moreira, M. A. Mapas conceituais como recurso instrucional e curricular. In: MOREIRA, M.A. A teoria da aprendizagem significativa e sua implantação em sala de aula. Brasília: Editora Universidade de Brasília, 2006. cap. 2.

Lima, M. A. B. (2019). Prazer e sofrimento no trabalho dos docentes da educação profissional em enfermagem. Plures Humanidades, 20(1).

Silva, W. R. S., de Souza, D. P., \& Moura, S. R. (2019, December). A abordagem PBL (Problem Based Learning) em um curso técnico em enfermagem: elementos autobiográficos da prática docente em anatomia humana. Revista Pesquisa Qualitativa - Sociedade de Estudos e Estudos Qualitativos, 7.

Rocha, M. B. (2021). (Re) Aprender a ensinar em tempos de Covid-19: discutindo os desafios na prática docente. Revista Práxis, 12(1 (sup)). 